\title{
Comparing Men's and Women's Experiences of Multiple Exclusion Homelessness
}

\author{
Graham Bowpitt*, Peter Dwyer**, Eva Sundin*** and Mark Weinstein **** \\ * School of Social Sciences, Nottingham Trent University \\ E-mail: graham.bowpitt@ntu.ac.uk \\ **School of Nursing, Midwifery and Social Work, University of Salford \\ E-mail:p.j.dwyer@salford.ac.uk \\ ***School of Social Sciences, Nottingham Trent University \\ E-mail: eva.sundin@ntu.ac.uk \\ ****Graduate School of Business, Law and Social Sciences, Nottingham Trent University \\ E-mail: mark.weinstein@ntu.ac.uk
}

This article explores gender as a variable in multiple exclusion homelessness in England. Much past research has taken insufficient account of the gender of homeless people, especially the predominance of men in the single homeless population and of women heading homeless households with dependent children. Drawing on qualitative data generated in a study of multiple exclusion homelessness in London and Nottingham, the article considers three ways in which gender may act as a homelessness variable: in people's susceptibility to homelessness, in their experiences of homelessness and in their encounters with accommodation services. By comparing the accounts of homeless men and women with complex support needs with evidence from staff working for support agencies, the overall aim of the article is to offer a critical examination of the gendered assumptions of homelessness policy and practice.

\section{Homelessness as a gendered experience}

Some time ago, Neale (1997) observed that the literature on housing and homelessness in England often suffers from gendered assumptions. Thus issues of gender are only raised when women's experiences are being examined, with the assumption that either the experiences of men are normative, or gendered aspects of men's experiences are irrelevant to their homelessness, and the significance of men predominating in the single homeless population has been largely ignored. Yet housing has long been recognised as one of the vehicles through which gender relations have been reflected, mediated and sustained (Davis, 2001), with the implication paradoxically that for women the home is not only a site of oppression, exploitation and male domination, but also 'a strong source of identity, pride and satisfaction' (Darke, 1994: 12). This understanding has conditioned our expectation of women's homelessness as both an escape and an intensely felt source of loss. The evidence that violence and harassment are the main triggers for women's homelessness in as many as 40 per cent of cases in the UK (Garner et al., 2003) is therefore not surprising. Research into women's homelessness has also suggested that the management of homelessness is similarly gendered, with single women negotiating their way through 'careers of homelessness' in ways that seek to conceal their homeless 
identity and sustain the trappings of domesticity (Parker and Fopp, 2004; Reeve et al., 2006, 2007). What is missing from research is an equivalent analysis of the causes and experiences of homelessness for men.

This assumption that women experience homelessness in ways that differ sharply from men is further reinforced in England by legislation which awards statutory rights to households deemed to be in 'priority need', typically those with dependant children, which are headed by women in the majority of cases (Shapps, 2008). However, single women may also gain priority by being 'vulnerable' because, for instance, they are fleeing violence, suggesting that women gain from statutory rights (Fitzpatrick, 2005). Yet this has been challenged by recent research, with less than a third of the homeless single women in Reeve et al.'s study being awarded priority need status for being vulnerable (2006). Nevertheless, the corollary of the assumption that most homeless women will have children and therefore basic housing rights is that most homeless people without children will be men, and this has done much to shape the pattern of social provision for homeless people in England which, historically, has had men in mind (Vincent et al., 1995). This is not only the product of statutory enactments, but it also taps a much deeper vein in western societies that sees the highway as the terrain of men, and therefore homelessness as a risk primarily for men (Wardaugh, 1999). The finding that women make up only 11 to 16 per cent of the single homeless population in England (Warnes et al., 2003; Broadway, 2009) reinforces this view. The result of this male orientation of homelessness provision has been a conditioning of expectations that has rendered homeless women invisible and emergency accommodation potentially dangerous to them. It follows that women are unlikely to sleep rough, preferring to find informal solutions to their homelessness through squatting and 'sofa-surfing' with friends.

The purpose of this article is to use evidence from a recent study to subject these assumptions to critical examination. In 2009/10, semi-structured interviews were undertaken with 105 homeless people (seventy-two men and thirty-three women) who satisfied multiple exclusion criteria. That is, they combined an experience of homelessness (rough sleeping, squatting or living in insecure accommodation) with one or more indicators of deep social exclusion (problematic substance use, chronic mental or physical ill health or an institutional background, such as prison, local authority care or asylum support). Samples were drawn mainly from the users of voluntary sector homelessness support services, including street outreach, day centres, hostels and supported housing. Additionally, semi-structured interviews were also conducted with forty-four key informants from statutory and voluntary sector services that have regular contact with homeless people.

This article compares men's and women's experiences of three 'moments' in their journeys through multiple exclusion homelessness: becoming homeless, managing homelessness and other complex needs and experiencing accommodation services. In the study, sampling was purposive to over-recruit women. The article compares men and women without current care of dependent children. The samples of men and women were broadly similar in terms of age, background and support needs, so that differences in the three variables under consideration can be attributed primarily to gender.

\section{Becoming homeless}

Fitzpatrick (2005) has summarised a 'new orthodoxy' that has emerged in theorising homelessness that seeks to combine 'structure' and 'agency' by showing how structural 
disadvantages limit people's capacity to respond to personal problems and tragedies. This still begs research into the processes by which these multiple exclusion factors combine to generate and sustain homelessness in some cases rather than others. McNaughton (2008) has focused on the importance of different kinds of capital economic (material resources), human (personal skills) and social (relationships and networks) - in conditioning people's capacity to deal with crises. One purpose of this article is to explore how far this process is differentiated along gender lines.

Respondents were asked to identify the factors that triggered homelessness events in their lives and to reflect on background experiences that may have put them at risk. When exploring the background experiences of our sample there are some notable similarities between homeless men and women. Around half of both men and women had suffered the bereavement of a close relative or a major trauma in their lives. Three quarters of both genders attributed their homelessness, at least in part, to family or relationship breakdown. Other background factors were more likely among men than women, but only marginally so. Thus nearly all the men had abused drugs and/or alcohol, compared with three quarters of the women. Half the men reported criminal behaviour and/or experience of prison, compared with just over a third of the women. Over two thirds of both genders had a mental illness, while a quarter of the women and slightly fewer men had been in local authority care. Half the men and nearly two thirds of the women reported using avoidant coping to deal with stressful or traumatic events, suggesting that some background factors were a response to others.

However, when considering the process by which background factors and experiences conspired to trigger homelessness, some significant differences by gender emerge. Thus men and women abandoned their accommodation in roughly equal proportions, but the factors lying behind these decisions varied. While women spoke of relationship breakdown, domestic violence and the presence of abusive relationships, men were far more likely to be motivated by emotional events connected to their families that they felt were out of their control. In this sense, men were walking away from what they saw as intolerable or complex family problems, while women were actually fleeing in order to protect their safety.

When he hit me I was in a coma ... He hit me one day and I thought, look the next time I might die. [I] ended up in hospital. They said if I had taken another blow to the head it could kill me. So I had to. I waited until he was sleeping in the night and took the kids and left ... in my night clothes. (Annie, London)

It all started when I was about $15 \ldots$ My mum and dad had a massive row one day. I said, 'Any more of this and I'm walking out.' Next thing my father got tanked up. Me and him had a barny ... Next thing, F off and what have you. Took me a couple of weeks to get there. I was at work, get on the bus, go to Victoria, just get out of it ... Enough is enough. I'm walking. I forced myself to do it ... Just go, don't look back. (Barry, London)

Other homelessness triggers included unsupported prison discharge, which was slightly more frequent among men because they were more likely to have experienced imprisonment. However, reasons for eviction from rented accommodation varied considerably by gender, with men more likely to be evicted for non-payment of rent, 
while women's eviction tended to follow abandonment by a partner whose name was on the tenancy agreement.

I stayed with my mum, moved back into my room at home. But then that went on and on: fifteen, sixteen, seventeen years. Then my mum died, so I was on the streets, because they didn't put my name on the tenancy. (Annie, London)

Basically I got a Council house; there had been a house fire in it, an electrical fault. The Council charged me with it, not for setting the fire necessarily, but for all the damage ... It weren't my fault. It came to about $£ 6,000$ and I couldn't afford to pay that, so they revoked my tenancy. (Darren, Nottingham)

Gendered differences in the underlying causes and precipitating factors in homelessness should not be allowed to obscure what men and women share, namely background factors that both ill-equip people to handle crises and render them more likely. Thus lives characterised by family breakdown, bereavement and other traumatic events, in the context of poverty, lack of affordable housing, institutionalisation, mental health problems and chronic substance abuse, both increase the likelihood of, for instance, eviction, domestic violence and abuse, and unsupported prison discharge, and reduce people's capacity to manage these events without generating homelessness. However, we found some evidence of differences of emphasis both in men and women's vulnerability to certain background factors, and the manner in which they managed them. Thus both men and women experience domestic violence, but women are more likely to be driven to flee for their own safety, whereas men seem more able to leave at a point of their choosing. Again, relationship breakdown in the context of a gendered housing market is more likely to leave women without tenancy rights than men. These are differences of degree, but they may say something about the gendered power structures that affect the vulnerabilities of men and women differently.

\section{Managing the experience of homelessness}

As previously noted, some commentators argue (for example, Parker and Fopp, 2004; Reeve et al., 2006, 2007) that people who come on to the streets encounter a highly gendered world of homelessness, populated predominantly by men in which services appear to presume a largely male population from which homeless women tend to remain hidden. The strength of this belief has led some to try to theorise its causes. Thus Wardhaugh (1999) distinguished between the ways men and women deal with the vulnerability of the 'homeless body'. Housing provides a 'second skin' that is vital to the body's security as the primary site of social experience. Lacking this protective layer, it is argued, homeless women will tend to 'contract' their bodies by rendering either themselves or their homelessness invisible to public scrutiny. In contrast, homeless men will do the opposite and 'expand' their bodies, seeking to colonise the streets and other public places to construct an alternative hard exterior. Some of our own key informants reinforced this view in suggesting, for instance, that homeless women rarely slept rough.

However, Reeve et al. (2006, 2007) have challenged this finding, showing that 60 per cent of their sample had slept rough at some point, and go on to demonstrate the ingenious ways in which women maintained the use of public places, challenging 
their homeless identity (Casey et al., 2008). May et al. (2007) have also argued that women's responses to homelessness are too complex to be reduced to a simple, gendered dichotomy. Noting women's rough sleeping, they reject the implication that women have taken on a male homeless identity in the interests of street survival. Instead, they developed Wardhaugh's dichotomy into a fourfold typology, distinguishing between those who distanced themselves from the homeless identity, those who existed 'in the shadows of the street homeless scene', those who identified more closely with the street homeless scene and those who assumed a quite different identity. Foremost among these alternative identities was that of 'street prostitute', an issue to which we will return. This section will seek to test these gendered characterisations of homelessness with evidence from our own study.

Our evidence points to an experience of rough sleeping among women that is almost as extensive as men's. Nearly all the men in our sample had slept rough, compared with about three quarters of the women. Both men and women gave graphic accounts of the hardships of street homelessness, including cold, hunger and an inability to attend to personal hygiene that presented distinct challenges to women.

I hated being homeless when you've got nowhere to go to toilet at night. That was the worst part ... I used to get really pissed off. I used to get really filthy. My clothes would be really manky. When you are on your period and you are a girl on the streets, that's the worst time. (Laura, London)

You can't change trainers ... for weeks on end. Same underpants for weeks on end. It's a killer. You can't get washed anywhere. (Craig, London)

Both men and women were equally familiar with the perils of street homelessness, challenging the notion that homeless men are able to 'colonise' the streets and construct an alternative hard exterior.

It's very dangerous being homeless, very, very dangerous. People home in on vulnerable people and then they let out their frustrations on them, because they think no-one's gonna say anything. I've seen that loads of times. People have been sleeping and then got beaten up purely because they're homeless and because that other person has got bad things going on in their head. (Barry, Nottingham)

I was on the streets with other people. I was too scared to sleep on my own on the streets. I was lucky to have people round me ... Not everyone who is homeless is friendly. They kick your head in. Get drunk. You have to be careful. It's dangerous ... (Laura, London)

However, whilst the experience of homelessness may have been similar for men and women, survival strategies highlight some gendered differences. For instance, men were more likely than women to resort to criminal behaviour as a survival strategy, either to secure money for drugs or to use prison as a source of accommodation.

I was fortunate. I was in prison a lot. If it got too bad on the streets, I'd get nicked, $£ 20$ for drugs. It was a safety net, prison. There was always a structure there. Even though I was locked 
up ... It was a relief. That pressure was off. Don't have to find money to buy food ... I used to get anxious when I left prison. (Henry, London)

By contrast, a number of women reported turning to sex work rather than seeking out prison as a way of surviving, but this carried its own risks.

Some of the guys were clients and others were with you for your money. They will smoke with you and they'll be like right it's your turn, you need to make a raise now coz I've paid for this so it's your turn now. A lot of them are dangerous you know, like they batter you and I mean really batter you. I was sat in a guy's [client's] car ... He [pimp] put the guy's window through and dragged me out through the front of the car to get me out of the car coz he had gone off on one. (Charlotte, Nottingham)

The link between homelessness and sex working is well recognised (Davis, 2001), and there is some evidence that homeless women may resort to unwanted sexual activity just to put a roof over their heads (Reeve et al., 2006). However, its role in managing homelessness is more complex than the above evidence of its use as a risky survival strategy might suggest. For instance, some writers have challenged the predominant view of sex working women as 'victims', citing evidence that sex work may be part of a strategy for surviving both homelessness and earlier abuse and for reclaiming a sense of identity and self-worth (McNaughton and Sanders, 2007; Harding and Hamilton, 2009).

Despite the gender differences we encountered in our examination of the experience of multiple exclusion homelessness, there was little to support the kind of radical dichotomy proposed by Wardhaugh (1999). Whilst recognising that our study was unable to penetrate the world of hidden homelessness, with regard to street homelessness it does appear that women sleep rough in numbers far in excess of those indicated by street head counts and other surveys. Our own findings suggest that, if anything, gender differences tend to dissolve in the face of the harsh realities of street life, with men as much at risk of violence and harassment as women, and equally likely to seek out the support of homeless companions (of either sex), and to find ways to avoid the perils of the street through sofa-surfing and other precarious forms of temporary shelter. Yet there was some evidence of variation in the way men and women manage the homeless experience, especially where homelessness is compounded by the need to maintain substance use. Thus men were more willing to revert to certain kinds of criminal activity, while women were more likely to engage in street sex work. These differences suggest that, in situations of desperation, the lives of multiply excluded homeless people reflect the realities of a gendered society.

\section{Encountering accommodation services}

The study also explored people's attempts to address their needs and sought to understand their responses to offers of help. Space does not allow a thorough review of the evidence (which will be presented in future work), but two channels of help - local authority housing services and hostels for single homeless people - warrant discussion here because of the gendered assumptions around which they have developed. The term 'hostel' is used here to include all residential facilities that are staffed continuously, although there is some variation in the degree of residents' independence, with some 
providing meals and others expecting residents to be self-catering. We noted earlier the reasons why local authorities might ascribe 'priority need' status to women more often than to men, but this was seldom born out in the experience of our sample. For instance, one woman was deemed not to be in priority need.

They said, 'you are not pregnant; you don't have any issues like mental issues so we can't help you' ... They didn't care. I explained my situation. There was my stuff and they ... say 'you have to arrange it with your sister' ... They didn't even tell me where to go to get help. I asked and they said, no we don't know. (Margaret, London)

Another woman was considered not to be homeless, despite fleeing intimidation, because she still technically owned the house from which she had escaped.

I didn't know where to turn to or anything so I went to the Council and they turned round and said I had to go back to my own house. I said I can't go back to my own house; he's changed all the locks ... She said, 'Well you'll have to get your keys off your ex-husband.' I said, 'I can't because I don't know where he lives.' 'Sorry but you've got your own house; there's nothing we can do.' (Natalie, Nottingham)

Sleeping rough, or at best sofa-surfing, was the immediate outcome in these cases. For those who were awarded statutory rights, temporary accommodation in a hostel was normally the outcome, at least in the first instance. It was therefore important to explore how far this avenue is equally appropriate to men and women. We have already noted the gendered assumptions that have shaped hostel provision for homeless people historically in England, but there is evidence that the character of that provision is changing. Dormitories have given way to self-contained flats, more amenable to accommodating both sexes. However, writers point to women's vulnerability and high rates of abandonment in mixed hostels, advocating instead either women-only hostels or segregated provision in mixed hostels (Eden and Vaccianna/The Lilith Project, 2005; Chandler and Cresdee, 2008). A female respondent confirmed this view, for example,

Unfortunately, I found the accommodation was unsuitable for me. I was a single woman in a hostel full of men. It was a small hostel and two or three of the guys they came in ... and took over. They didn't sound particularly nice people to me. I wasn't able to get in and out of my hostel room without encountering them. (Melissa, London)

Nearly all respondents had had some experience of hostels, even those currently street homeless. Just over a quarter described their stay as a positive experience. The only clear gender difference was that men were far more likely to have experienced eviction.

The first time I became homeless, I got into the [name of hostel] and then they kicked me out because I was drunk and disorderly ... The second night I was there I had a fight with this guy. I chucked some boots at the wall and smashed a mirror. That was a bad mistake. They kicked me out of there and that's when I was homeless again. (Kevin, Nottingham)

A minority of both genders reported that they avoided hostels, had problems accessing them or left of their own accord. Others reported negative experiences such as living in 
a hostel making their drug problems worse or instances of being bullied or victimised, with women feeling particularly vulnerable in hostels where men were in the majority. However, experiences of intimidation were by no means unique to women.

Ever since I was in my last hostel I got introduced to crack-cocaine and ketamine and that was it. But this is the worst hostel I've been in. Everyone does it. There is not one person that doesn't do drugs or alcohol. They all do it. (Wayne, London)

Someone was bullying me in the hostel. Even though I was in a hostel, people still come round to take your giro off you. The staff didn't do much about it. They said if you say anything I'll kick your head in. Because I was off my face all the time and paranoid and things like that, I was paranoid about getting knifed. I was vulnerable. (Steve, London)

Our findings revealed little evidence of clear differences between men's and women's experiences of these accommodation responses to multiple exclusion homelessness. In the absence of dependent children, women are no more likely than men to be given priority treatment by local authorities. Neither was there anything to suggest that variations in people's experiences of, and attitudes towards, hostel accommodation can be attributed to gender differences alone. To some, hostels are sanctuaries that give access to privacy and dedicated support staff through whom complex needs can be addressed. To others, they are hostile places that subject vulnerable individuals to harassment, intimidation and the ever-present pressures of harmful substance use. This was true for both the homeless men and women in our study. The only clear difference was in the greater likelihood of men dealing with these risks in violent ways and getting evicted as a result, though evidence elsewhere suggests that, in women only hostels, bullying is a prevalent problem that avoids this effect by remaining hidden from staff (McNeill, 2007).

\section{Conclusions}

This article has used data from a recent study of multiple exclusion homelessness in Nottingham and London to advance our understanding of the comparable experiences of men and women in becoming, experiencing and addressing homelessness in the context of other complex needs. The study was limited to people who had made some use of services (if only day centres and other street level services for rough sleepers), and was therefore unable to penetrate the world of hidden homelessness.

The overall thrust of our findings is that while there are many similarities in the way men and women experience or address multiple exclusion homelessness, they do so in the context of a society in which people's opportunities and vulnerabilities are governed by gender relations and associated expectations. A background of violence in the home was a common experience in the lives of many of our sample. Men and women were evicted by other householders in roughly equal numbers, but women were more likely to be driven to flee their abusers than men. Periods of squatting and rough sleeping were only slightly less likely among women than men who were equally exposed to risks of violence and harassment in the process. However, gendered differences in approaches to street survival were reflected in the way homelessness was more likely to be associated with criminal activity among men, but street sex work among women. Moreover, we found little evidence that homelessness legislation and the availability of women's refuges give single women fleeing violence a kind of privileged route to avoiding 
street homelessness. Women without current care of dependent children fare no better than men in their dealings with local authority housing services. Furthermore, whilst many hostel providers have taken steps towards making their accommodation more accessible to women, many women still encounter an environment in which men predominate and which they perceive as hostile. Yet even here, our study revealed the extent to which men were also exposed to the pressures of intimidation, theft and harmful substance use associated with hostel life.

Further research is still needed into the disparate levels of single homelessness found between women and men. Do men genuinely come on to the streets in greater numbers than women, and if so why? Conversely, do the figures obscure a higher degree of hidden homelessness among women, as some have suggested? These questions could only be answered using methods quite different from our own, ones that are less reliant on people making their homelessness public through accessing support services. What our research has succeeded in showing is that, once on the streets, homelessness exposes men and women to the same degree of risk, and services give no preferences to either.

\section{Acknowledgements}

We would like to thank all those who participated in the study. Particularly, the two teams of formally homeless people who agreed to act as peer researchers for the interviews with homeless people and Debra Ives at Thames Reach, London, and Rachel Harding at Framework Housing Association, Nottingham This research was supported by the ESRC under grant number RES-188-25-0001.

\section{References}

Broadway (2009), Profiling London's Rough Sleepers: A Longitudinal Analysis of CHAIN Data, London: Broadway, http://www.broadwaylondon.org/Researchlnformation/Research/ProfilingLondonsRough Sleepers [accessed 13.07.2009].

Casey, R., Goudie, R. and Reeve, K. (2008), 'Homeless women in public places: strategies of resistance', Housing Studies, 23, 6, 899-916.

Chandler, T. and Cresdee, S. (2008), 'Climbing Everest Naked': The Revolving Door Research Project, Brighton: Health and Social Policy Research Centre, University of Brighton, http://www.brighton.ac. uk/sass/research/publications/revolving_door.pdf [accessed 19.11.2008].

Darke, J. (1994), 'Women and the meaning of home', in R. Gilroy and R. Woods (eds.), Housing Women, London: Routledge.

Davis, C. (2001), 'Gender and housing', in M. Harrison and C. Davis (eds.), Housing, Social Policy and Difference, Bristol: The Policy Press.

Eden, I. and Vaccianna, H. The Lilith Project (2005), A Woman's Place: Women and Hostel Provision in London, London: Eaves Housing for Women, http://www.eaves4women.co.uk/Lilith_Project/ Documents/Reports/lilith_hostel_report.pdf [accessed 09.02.2009].

Fitzpatrick, S. (2005), 'Explaining homelessness: a critical realist perspective', Housing, Theory and Society, 22, 1, 1-17.

Garner, F., Skinner, J. and Harding, R. (2003), The Needs of Homeless Women and Homeless Women with Children, Nottingham: Framework Housing Association, http://www.frameworkha.org/ write/publ/466SRB5_full_report.pdf [accessed 28.05.2008].

Harding, R. and Hamilton, P. (2009), 'Working girls: abuse or choice in street level sex work? A study of homeless women in Nottingham', British Journal of Social Work, 39, 6, 1118-37. 
May, J., Cloke, P. and Johnsen, S. (2007), 'Alternative cartographies of homelessness: rendering visible British women's experiences of "visible" homelessness', Gender, Place and Culture, 14, 2, 121-40.

McNaughton, C. (2008), Transitions through Homelessness: Lives on the Edge, Basingstoke: Palgrave Macmillan.

McNaughton, C. and Sanders, T. (2007), 'Housing and transitional phases out of "disordered" lives: the case of leaving homelessness and street sex work', Housing Studies, 22, 6, 885-900.

McNeill, J. (2007), 'Coping with homelessness: an exploration of homeless women's experiences', unpublished MSc dissertation, Nottingham Trent University.

Neale, J. (1997), 'Theorising homelessness: contemporary sociological and feminist perspectives', in R. Burrows, N. Pleace and D. Quilgars (eds.), Homelessness and Social Policy, London: Routledge.

Parker, S. and Fopp, R. (2004), "I'm the slice of pie that's ostracised...": Foucault's technologies and personal agency in the voice of women who are homeless', Housing, Theory and Society, 21, 4, $145-54$.

Reeve, K., Casey, R. and Goudie, R. (2006), Homeless Women: Still Being Failed Yet Striving to Survive, London: Crisis, http://www.crisis.org.uk/publications/Crisis_Homeless_Women_2006_full_report.pdf [accessed 24.04.2008].

Reeve, K., Casey, R. and Goudie, R. (2007), Homelessness Careers, Homelessness Landscapes, London: Crisis, http://www.crisis.org.uk/publications/Homeless_Women_Landscapes_Aug07.pdf [accessed 24.04.2008].

Shapps, G. (2008), Women and Homelessness: A Report into the Dramatic Rise in the Number of Women Stranded without Homes, http://www.shapps.com/reports/Women_and_Homelessness.pdf [accessed 27.10.2008].

Vincent, J., Deacon, A. and Walker, R. (1995), Homeless Single Men: Roads to Resettlement?, Aldershot: Avebury.

Wardhaugh, J. (1999), 'The unaccommodated woman: home, homelessness and identity', The Sociological Review, 47, 1, 91-109.

Warnes, A., Crane, M., Whitehead, N. and Fu, R. (2003), Homelessness Factfile, London: Crisis, http://www.crisis.org.uk/publications/factfile_Full.pdf [accessed 23.05.2008]. 